\title{
Flow Patterns, Pressure Drops and Other Related Topics of Two-phase Gas-liquid Flow in Microgravity
}

\author{
Jian-Fu ZHAO \\ Key Laboratory of Microgravity (National Microgravity Laboratory)/CAS; \\ Institute of Mechanics, Chinese Academy of Sciences (CAS) \\ China
}

\section{Introduction}

Two-phase gas-liquid systems have wide applications both on Earth and in space. On Earth, they occur in a variety of process equipment, such as petroleum production facilities, condensers and re-boilers, power systems and core cooling of nuclear power plants during emergency operation. The potential space applications include active thermal control system, power cycle, storage and transfer of cryogenic fluids, and so on. Reliable design of such systems requires a thorough understanding of the mechanism of two-phase flow, such as the phase distributions (flow patterns), pressure drops and heat transfer coefficients at different gas and liquid flow rates. Among them, flow patterns will play an important role because of strong influence of the phase distributions on pressure drops and heat transfer coefficients and thus attract more attentions of the academic and technical communities all over the world.

With the aid of numerous meticulous experiments, our present knowledge on two-phase gas-liquid systems has been built. It is, however, far from complete due to the complicate influence of gravity which is a dominant factor in normal gravity. Gravity strongly affects many phenomena of two-phase gas-liquid systems by creating forces in the systems that drive motions, shape boundaries, and compress fluids. Furthermore, the presence of gravity can mask effects that ever present but comparatively small. Depending on the flow orientation and the phase velocities, gravity can significantly alter the flow patterns, and hence the pressure drops and heat transfer rates associated the flow. Advances in the understanding of two-phase flow have been greatly hindered by masking effect of gravity on the flow. Therefore, the microgravity researches will be conductive to revealing of the mechanism underlying the phenomena, and then developing of more mechanistic models for the two-phase flow and heat transfer both on Earth and in space.

Research on two-phase gas-liquid flow in microgravity has a history of more than 50 years with a short pause in the 1970s and has been advanced with the development of various microgravity facilities and with increased experimental opportunities, especially in the last two decades. Due to much strict restriction on flight chance, weight and size of the test facility, power supply, and so on, studies on two-phase gas-liquid flow in microgravity are 
much limited. Furthermore, few experiments have been conducted in real microgravity environment. Most data are obtained from experiments performed in short-term reduced gravity with a relatively large value and equivalent pulsation of the residual gravity aboard parabolic airplanes. However, some advances, particularly on flow patterns of two-phase flow in microgravity have been made. On the progress in this field, many comprehensive reviews and monographs are available now. Among many others, Hewitt (1996), McQuillen et al. (1998), Gabriel (2007) and Zhao (2010) summarized the experimental and theoretical works all over the world. The first two papers provided the status of this field at the beginning of our research, while the last one presented a brief review of our researches in the past years.

Since the middle of 1990's, a series of microgravity research projects on two-phase gas-liquid flow in microgravity have been conducted in the National Microgravity Laboratory/CAS (NMLC). These activities cover experimental and theoretical studies on classification of flow patterns, transition criteria between different flow patterns, and pressure drops of twophase gas-liquid flows in pipelines, as well as some other related topics such as the characteristics of phase distribution inside flow fields and their influence on the performance of direct methanol fuel cells and proton exchange membrane fuel cells. In the following sections, the results obtained in these researches will be presented.

\section{Two-phase gas-liquid flows in pipelines in microgravity}

\subsection{Microgravity flow pattern transition models}

Our first activity in this field is re-analyzing the existing database and models/correlations in the literature up to 1998 on flow patterns of two-phase gas-liquid flows in straight, circular pipe in microgravity (Zhao, 1999). Major attentions focus on the classification of the flow patterns and the development of flow pattern maps of adiabatic two-phase gas-liquid flows in pipelines in microgravity. Because the influence of buoyancy is removed or weakened strongly, two-phase flows in microgravity are believed inherently simpler than those in normal gravity. For example, although other flow patterns appearing essentially in the transition zones are classified by some researchers, annular, slug, and bubble flows are usually considered as the major two-phase flow patterns in straight pipes in microgravity. Thus, there are two major transitions need to be modeled in microgravity.

For predicting the slug-to-annular flow transition in microgravity, the void fraction matched model proposed by Dukler et al. (1988) and modified by Colin et al. (1991) and Bousman (1995) is commonly used. For the case of turbulent liquid and gas phases, this model can be rewritten as following (Zhao, 2000)

$$
C_{0}=\left\{\alpha+\left[\zeta \Phi(1-\alpha)^{2}\right]^{5 / 9} \alpha^{-1 / 3}\right\}^{-1}
$$

As shown in Fig.1, it is possible that there will be 0,1, or 2 solutions in this model according to the different values of the phase distribution parameter $C_{0}$ in the drift-flux model and the material parameter $\zeta=\left(\rho_{G} / \rho_{L}\right)\left(v_{G} / v_{L}\right)^{1 / 5}$ (here $\rho$ and $v$ denote the density and viscosity 
respectively, while the subscripts $G$ and $L$ denote the gas and liquid phase respectively). The solutions will alter if different correlations for interfacial friction factor $\Phi$, such as those proposed by Wallis (1969) and Chen et al. (1991), are used. Furthermore, the suggestion of Dukler (1989) that the slug-to-annular flow transition will take place at the solution of smaller void fraction a is not a feasible criterion. For example, such a solution may locate in bubble flow regime for the case of $\zeta=0.001$, which approximates to the experimental condition of Dukler et al. (1988).

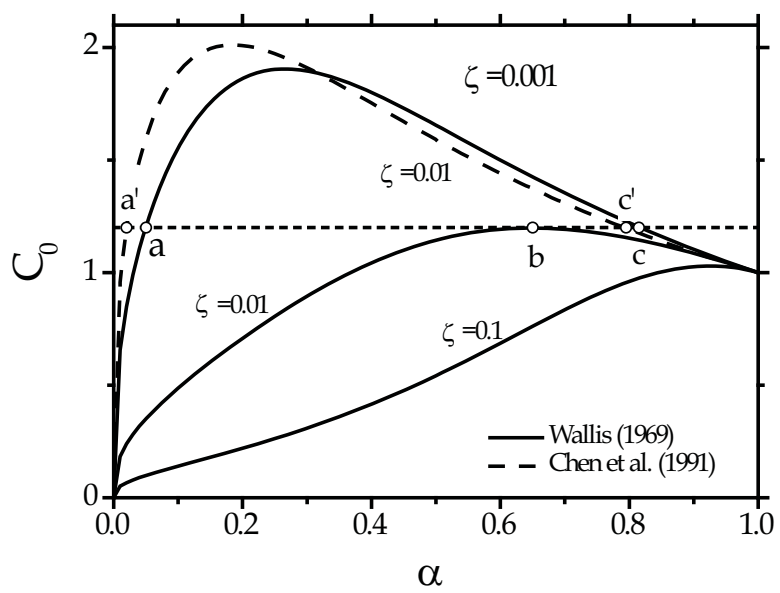

Fig. 1. Characteristics of the solution of the void fraction matched model for the slug-toannular flow transition in microgravity (Zhao, 2000).

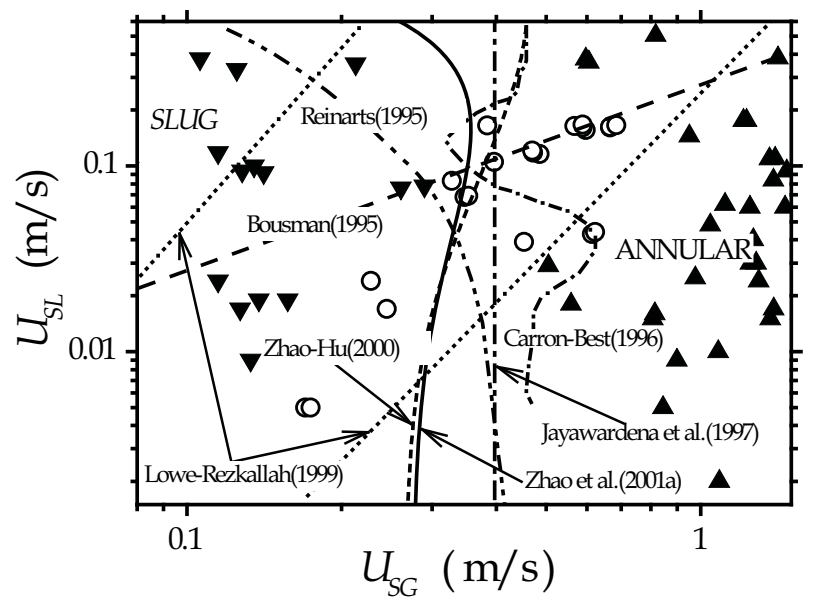

Fig. 2. Comparisons of the semi-theoretical Weber number model with the experimental data of Reinarts (1993) and other commonly used models. Symbols $\boldsymbol{\Lambda}, \boldsymbol{\nabla}$, and o denote slug, annular, and transitional flows, respectively (Zhao, 2010). 
A semi-theoretical Weber number model was developed firstly by Zhao \& Hu (2000), and later modified by Zhao et al. (2001a), which was based on the balance between the impulsive force due to the gas inertia and the surface tension force near the slug-toannular flow transition in microgravity. This model can be written in the following dimensionless form

$$
\left\{\begin{array}{c}
W e_{S G}=\frac{\rho_{G} U_{S G}^{2} D}{\sigma}=\frac{\kappa \psi C_{0}(1-\alpha) \alpha^{3 / 2}}{C_{0}-1} \\
q=\frac{U_{S L}}{U_{S G}}=\frac{1-C_{0} \alpha}{C_{0} \alpha}
\end{array}\right.
$$

where $D, \sigma, U S G$, and USL denote respectively the pipe diameter, the surface tension, the superficial velocities of the gas and liquid phases, $\psi$ denotes the geometrical corrector of the pipe cross-section (e.g. $\psi=4$ for a circular pipe while $\psi=2 \sqrt{\pi}$ for a square one), while $\mathrm{K}$ is an empirical parameter with an order of 1 . As shown in Fig.2, the model can provide an improvement of the accuracy in comparison with others. It was also proved to be accurate over a rather wide range of working fluids, tube diameters, and experimental methods including both flight experiments and ground simulated tests such as capillary gas-liquid experiments and equi-density, or neutral buoyancy, immiscible liquid-liquid experiments on the ground.

For predicting the bubble-to-slug flow transition in microgravity, the drift-flux model (Dukler et al., 1988; Colin et al., 1996) was commonly used in the literature.

$$
\begin{gathered}
q=\frac{1-X_{c r}}{X_{c r}} \\
X_{c r} \triangleq C_{0} \alpha_{c r}= \begin{cases}0.54, & \left(S u<1.5 \times 10^{6}\right) \\
0.24, & \left(S u>1.7 \times 10^{6}\right)\end{cases}
\end{gathered}
$$

where $\alpha_{c r}$ denotes the critical void fraction corresponding to the bubble-to-slug transition, while $S u=\sigma D \rho_{L} / \mu_{L}^{2}$ is the liquid Suratman number. The empirical model proposed by Jayawardena et al. (1997) can also be re-written in the same form with the following transition quantity $\mathrm{Xcr}$

$$
X_{c r}=K_{1} \frac{v_{G}}{v_{L}} /\left(K_{1} \frac{v_{G}}{v_{L}}+S u^{2 / 3}\right)
$$

It was, however, found that there exists an obvious difference between bubble flows in miniscale channels in normal gravity and those in normal channels in microgravity. It may arise from the difference of the relative bubble initial size in the two cases. A Monte Carlo method was then used to simulate the influence of the initial bubble size $d_{b}$ on the bubble-to-slug flow transition based on the bubble coalescence mechanism (Zhao, 2005). It was found that the dimensionless rate of collision is a universal function of the dimensionless bubble 
diameter $d_{b} / D$, and that the bubble initial size can affect the bubble-to-slug flow transition when its dimensionless value locates in the range from 0.03 to 0.4. Assuming the transition void fraction $\alpha_{c r}$ depends only on the dimensionless collision rate, the following correlation was obtained for the critical void fraction in this range,

$$
\alpha_{c r}=0.60-2.32 d_{b} / D
$$

which agreed well with the experimental data (Fig. 3).

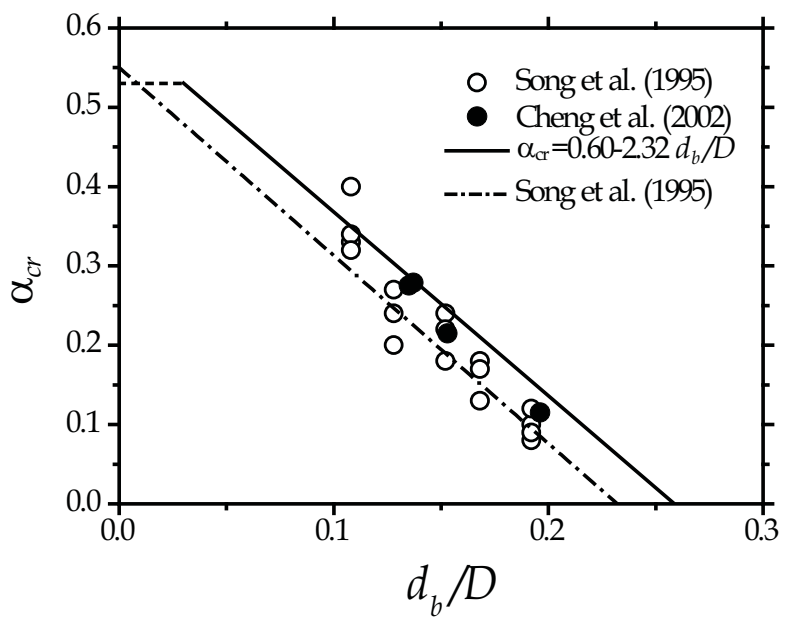

Fig. 3. The influence of bubble initial size on the transition void fraction for the bubble-toslug flow transition (Zhao, 2005).

\subsection{Two-phase flow pattern maps in microgravity}

Another major activity of us is to perform experiments on two-phase flow both in microgravity environment aboard the Russian space station Mir and IL-76 parabolic airplane and in simulated microgravity conditions using capillary gas-liquid experiments on the ground. Several sets of data on two-phase flow patterns have been collected from these experiments, which are helpful both to understand the mechanism underlying the phenomena and to design two-phase systems operating on board spacecrafts and/or satellites.

Collaborating with researchers from the Keldysh Research Center of Russia, an experimental study was conducted on two-phase flow patterns in a circular pipe with an inside diameter of $10 \mathrm{~mm}$ and a length of $356 \mathrm{~mm}$ aboard the Russian space station Mir in August 1999 (Zhao et al., 2001b, c), which is the first opportunity and also the sole one up to now to have data from an experiment conducted in a long-term, steady microgravity environment. Air was used as the gas phase, while carbogal, an odorless, colorless and nontoxic liquid with a small contact angle $\left(0 \sim 7^{\circ}\right)$ with the test tube, was used as the liquid phase. Bubble, slug, and annular flow were observed as in other researches. Fine dispersed bubble flow was observed at higher liquid superficial velocity, while a wider region of slugannular flow was also observed at moderate gas superficial velocity. A new region of 
annular flow with smooth interface at much lower liquid superficial velocity was discovered firstly, which can not be interpreted presently (Fig. 4).

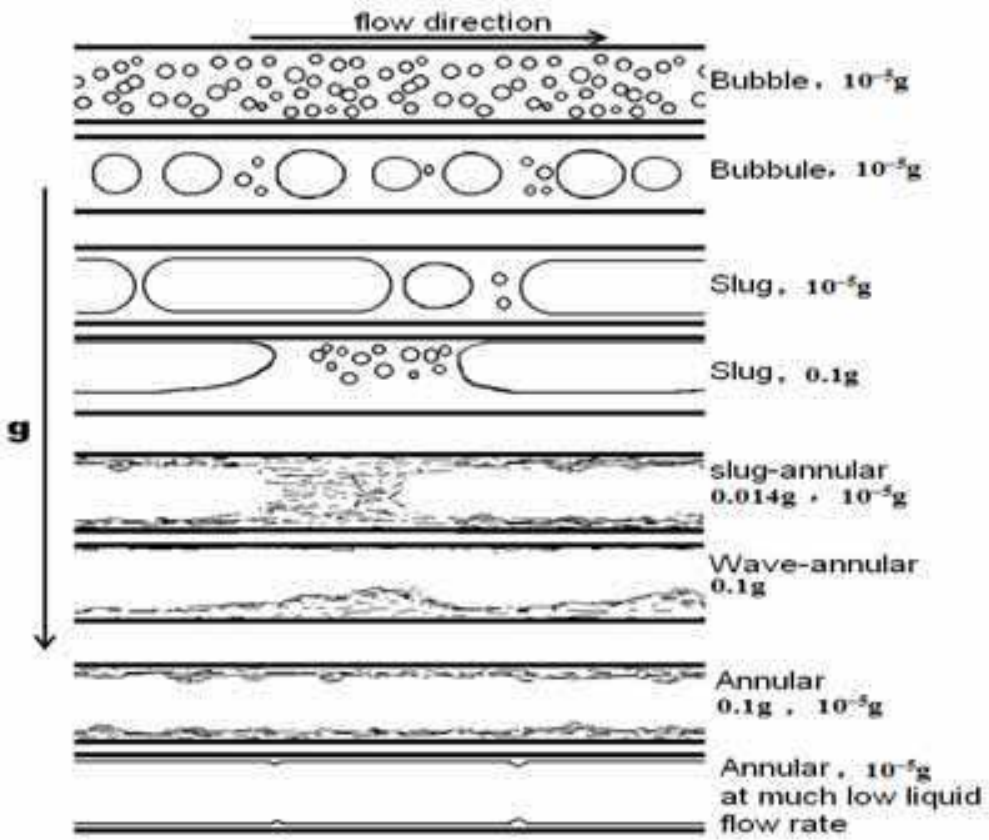

Fig. 4. Typical flow patterns in different gravity conditions aboard the space station Mir (Zhao et al., 2001b,c).

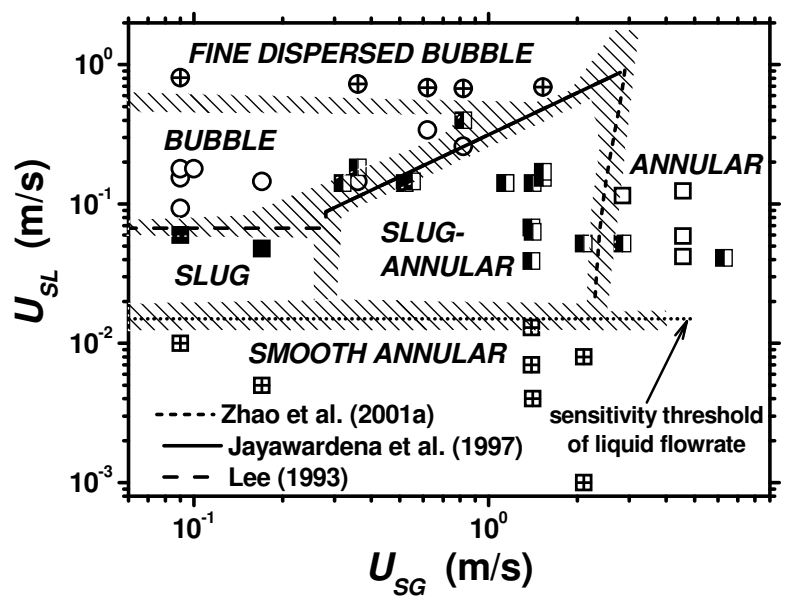

Fig. 5. Flow pattern map of two-phase flow in microgravity aboard the space station Mir (Zhao et al., 2001b). 
With detailed comparisons between the reliable data obtained aboard the space station Mir and the predictions of the models proposed in the literature, it was indicated that the observed flow patterns at low gas superficial velocity should be considered to be developing ones due to the small length-to-diameter ratio. The entrance effects were much weak on the flow pattern transitions at moderate and high gas superficial velocity. A comprehensive flow pattern map (Fig.5) was provided according to the results in the background microgravity environment aboard the space station Mir. Data in partial gravity conditions provided by rotating the experimental facility with constant velocities aboard the space station Mir were also reported by Zhao et al. (2004b).

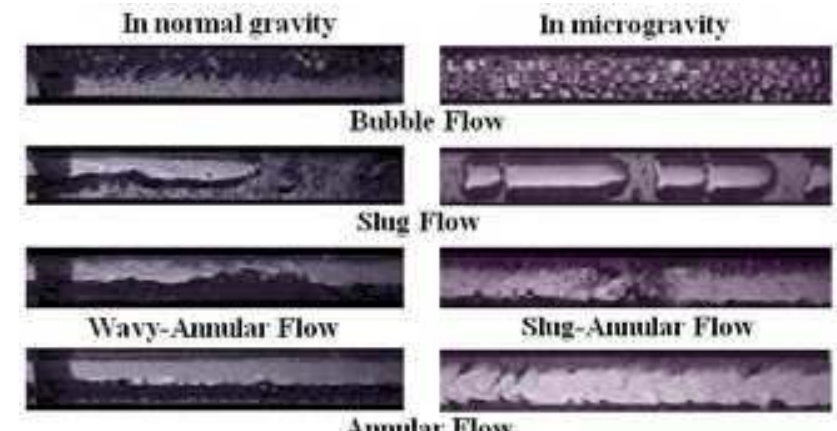

Annular Flow

Fig. 6. Typical flow patterns in a square channel in different gravity conditions (Zhao et al., 2001a).

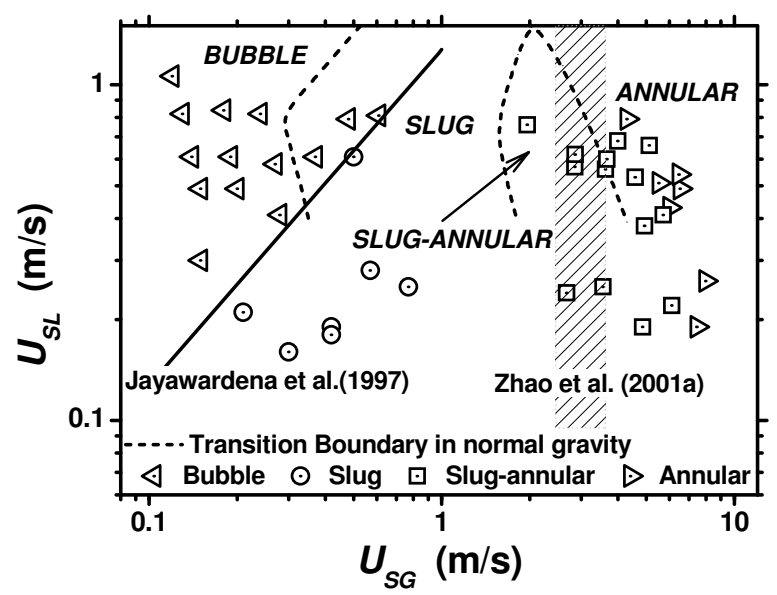

Fig. 7. Flow pattern map of water-air flow in a square channel in microgravity (Zhao et al., 2001a).

Another experimental research was conducted on two-phase water-air flow patterns in a $12 \times 12 \mathrm{~mm} 2$ square channel aboard the Russian IL-76 reduced gravity airplane in July 1999 (Zhao et al., 2001a). Bubble, slug, slug-annular, and annular flows were observed in different 
gravity conditions (Fig. 6). The flow pattern map obtained in microgravity was shown in Fig. 7, while that obtained from the ground control tests in normal gravity was also shown for comparison. If the slug-annular flow is considered as no one of the major flow patterns but a transitional one between the slug and annular flows, the semi-theoretical Weber number model of Zhao \& Hu (2000) with the improvement about the shape influence can predict well the slug-to-annular flow transition both in normal and in microgravity. The prediction by Jayawardena et al. (1997) was also in reasonable agreement with the observed boundary between bubble and slug flows in microgravity. Furthermore, it was found that the transition void fraction for the bubble-to-slug flow transition with large Froude number in normal gravity is in direct proportion to the gas relative area in the channel cross-section and its counterpart in microgravity.

Two-phase flow patterns in a $90^{\circ}$ bend in microgravity were analyzed by Zhao \& Gabriel (2004). The experimental data were obtained by the Microgravity Research Group at the University of Saskatchewan, Canada. Three major flow patterns, namely slug, slug-annular, and annular flows, were observed in this study (Fig. 8). The transitions between adjoining flow patterns were found to be more or less the same as those in straight pipes, and can be predicted satisfactorily by the Weber number models (Zhao \& Hu, 2000; Lowe \& Rezkallah, 1999). Attention was also paid to the difference of the flow structure between single- and two-phase flows. The bullet-shaped bubbles in slug flow and the gas core in annular flow usually exhibited imposed rotation, which could be inferred from the obvious striations on the gas-liquid interface spreading from the inside to the outside at an acute angle to the forward direction. It may arise from the secondary liquid flow in the bend, which is modified by the presence of the gas phase. This information will be valuable for more sophisticated modeling of two-phase flow in bends in the future.
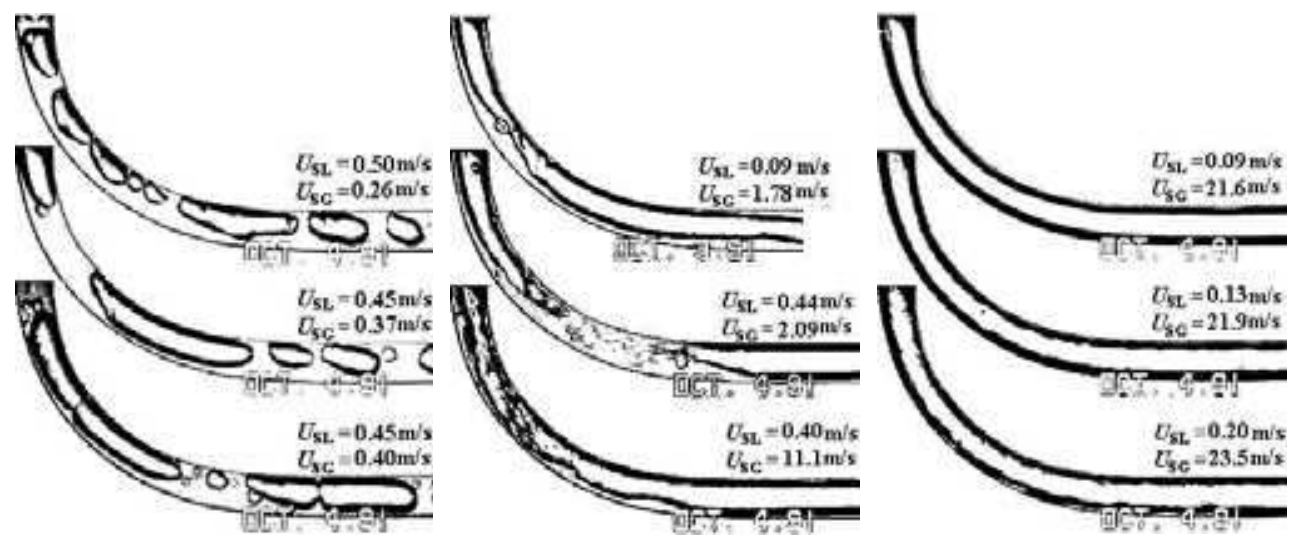

Fig. 8. Flow patterns in $90^{\circ}$ bend in microgravity (Zhao \& Gabriel, 2004).

Mini-scale modeling was also used to simulate the behavior of two-phase flow in microgravity (Zhao et al., 2004a). A $1 \times 1 \mathrm{~mm}^{2}$ square mini-channel was used. A mixer with four $0.7-\mathrm{mm}$ holes perpendicular to the channel axis was located before the channel. The experimental data were compared with other data in mini-channels reported in literature, and also compared with those in normal channel in microgravity, in which the Bond number had the same order of magnitude. The transition to annular flow was consistent in 
all cases (Fig. 9). Comparing with the prediction of the empirical relation of Jayawardena et al. (1997), a much smaller value of the transition void fraction was obtained for the bubbleto-slug flow transition in mini-channels. Obvious difference was found between bubble flow in mini-scale experiments and that in microgravity experiments (Fig. 10). As discussed above, it may arise from the difference of the relative bubble initial size in the two cases. Thus, the mini-scale modeling can be used to anticipate the behavior of two-phase flows with high flow rates through normal size channels in microgravity, while it can not be an effective way for simulating the behavior of microgravity two-phase bubble flows.

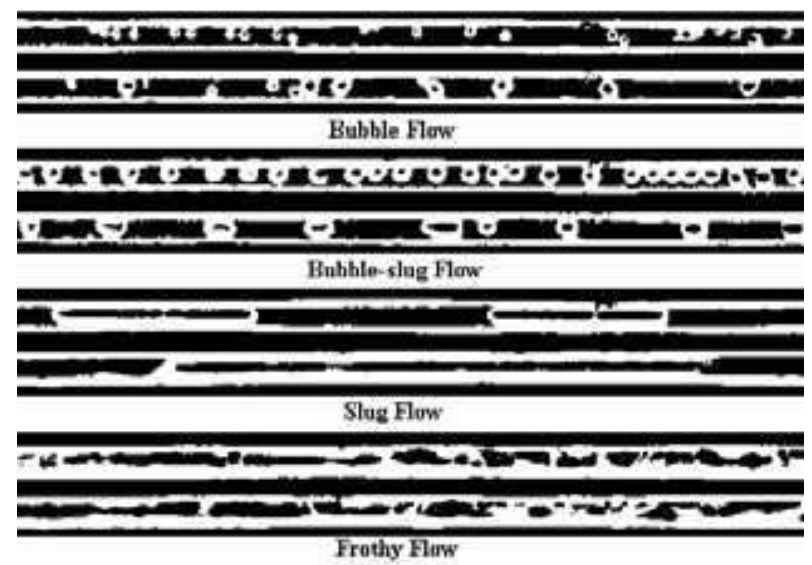

Fig. 9. Typical flow patterns of water-air flow in a $1 \times 1 \mathrm{~mm}^{2}$ capillary square pipe on the ground (Zhao et al., 2004a).

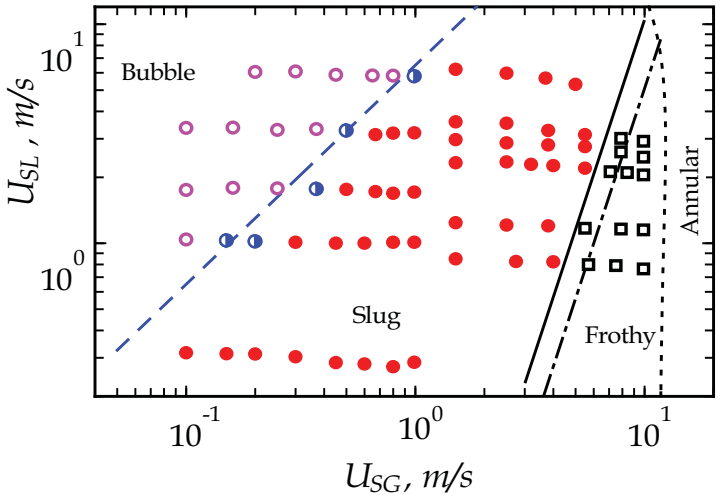

Fig. 10. Flow pattern map of water-air flow in a $1 \times 1 \mathrm{~mm}^{2}$ capillary square pipe on the ground (Zhao et al., 2004a).

\subsection{Pressure drop of two-phase flow in microgravity}

In the experiment aboard the Russian IL-76 reduced gravity airplane in July 1999, pressure drops of two-phase flow in microgravity were also measured and compared with some 
commonly used correlations in the literature (Zhao et al., 2001d), such as the homogenous model, the Lockhart-Martinelli-Chisholm model, and the Friedel model. It was found that much large differences exist between the experimental data and the predictions. Among these models, the Friedel model provided a relative good agreement with the experimental data (Fig. 11). A more accurate model should be developed based on a more physical analysis of flow characteristics and a large empirical database developed with the aid of numerous meticulous experiments both in normal and reduced gravity.

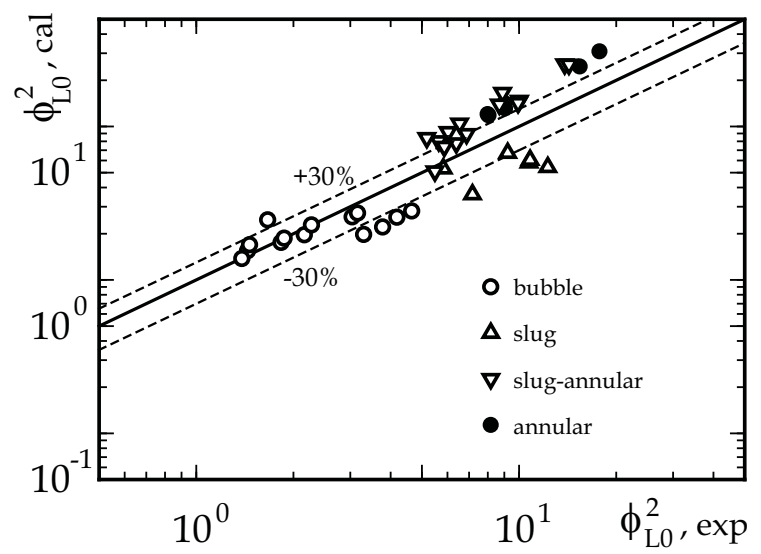

Fig. 11. Comparison of two-phase pressure drop in microgravity with Friedel's correlation (Zhao et 1., 2001d).

Based on the analysis of the flow structure of two-phase bubble flow in microgravity, it was suggested by Zhao et al. (2002) that the friction factor and the Reynolds number in this case should be defined based on the mixture velocity $U m$ and the properties of the liquid phase, namely

$$
f_{T P}=\left[(d p / d z)_{F} D\right] /\left(2 \rho_{L} U_{m}^{2}\right) \text { and } R e_{T P}=\rho_{L} U_{m} D / \mu_{L}
$$

respectively. A semi-theoretical relationship, i.e.

$$
f_{T P}=A R e_{T P}^{-1}
$$

was also proposed, in which the parameter $A$ is dependent on the Reynolds number and should be determined empirically. Comparing the present data in the square channel and those collected by Zhao \& Rezkallah (1995) and Bousman (1995) in circular pipes, little influence of the cross-sectional shape was found (Fig. 12). Constant values of the parameter A, namely $A=35$ for $R e_{T P}<3000$ and $A=120$ for $R e_{T P}>4000$, were obtained. It was indicated that there exists a transition of flow structure in the range of $3000<R e_{T P}<4000$, similar to the laminar-to-turbulent transition in single-phase pipe flow. A further comparison, however, with the data obtained by Colin (1990) showed that an exponent for the Reynolds number between 0 and -1 should be more suitable for the case of large Reynolds number. 


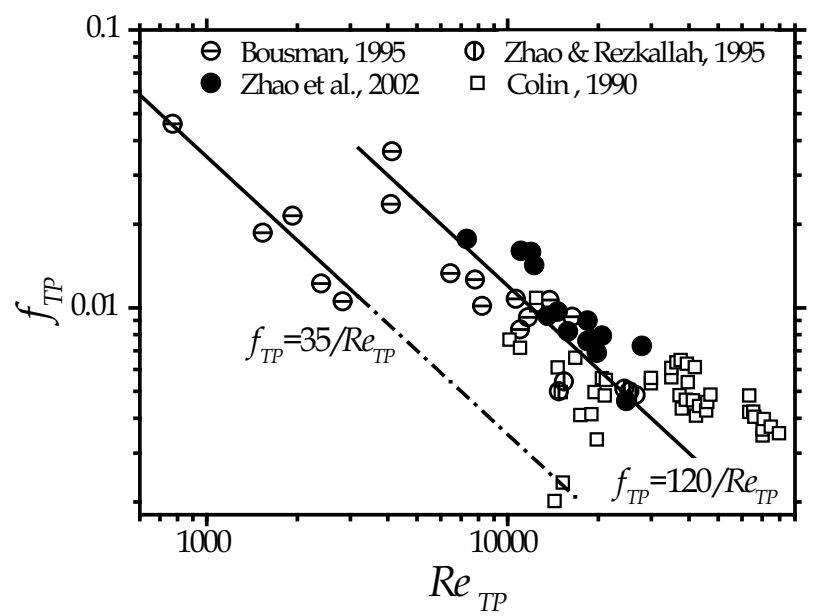

Fig. 12. Pressure drop of two-phase bubble flow in microgravity (Zhao, 2010).

\section{Phase distribution and performance of fuel cells in microgravity}

Electrolysis cells and fuel cells will be major parts of regenerative environmental control and life support systems (ECLSS) for a long-term manned space flight mission. Electrolysis/fuel cells may be operated in different gravity condition during different flight stage. Two-phase flow inside cells may exhibit different characteristics and then affect their performances, even cause some severe problems of safety. Thus, study the phase distribution and corresponding electric performance of electrolysis/fuel cells plays an important role for the design of such systems related to space applications.

Collaborating with Profs. H. Guo and C. F. Ma at Beijing University of Technology, a serial of experiment projects have been proposed to study the phase distribution and corresponding electric performance of electrolysis/fuel cells in different gravity conditions in our group by utilizing the drop tower Beijing to provide a short-term microgravity environment.

At first, a small liquid fed direct methanol fuel cells (DMFC) was used as a simplified model. A commercially available MEA was sandwiched between two graphite bipolar plates with sealing gasket. The MEA with an active area of $5.0 \times 5.0 \mathrm{~cm}^{2}$ consists of a Nafion 117 membrane and two carbon cloth gas diffusion layers. The catalyst loading was 4 $\mathrm{mg} / \mathrm{cm}^{2} \mathrm{Pt} / \mathrm{Ru}$ on the anode side and $4 \mathrm{mg} / \mathrm{cm}^{2} \mathrm{Pt}$ on the cathode side. Electric resistors were employed as external circuit load. Both the anode and the cathode bipolar plates were made of graphite and consisted of channel area, extension area and location pinholes. Extension area of both the anode and the cathode plates was used as current connector. A single serpentine channel, which had rectangular cross section of $2.0 \mathrm{~mm}$ in depth and 2.5 $\mathrm{mm}$ in width, was fluted in cathode flow field. The rib width is $2.0 \mathrm{~mm}$ and the channel length was $566 \mathrm{~mm}$. In order to preheat the fuel cell, a heater was stuck to the cathode bipolar plate. The channel area of anode bipolar plate had 2 manifolds and 11 parallel straight channels, whose length was $48.0 \mathrm{~mm}$. Each channel had rectangle cross-section with depth of $2.0 \mathrm{~mm}$ and width of $2.5 \mathrm{~mm}$. The width of rib, which was between two adjacent channels, was $2.0 \mathrm{~mm}$. For the purpose of visual observation, the end plate of the anode side 
was made of transparent polycarbonate (PC). A high-speed video camera (VITcam CTC) with a CCTV C-mount lens (SE2514, AVENIR) was employed to capture two-phase flow images in the anode flow field. A shutter speed of $3996 \mu \mathrm{s}$, a recording speed of 250 frames/s and a resolution of $1280 \times 1024$ pixels were set to visualize and record two-phase flow in the anode flow field.

Oxygen gas with purity of $99.999 \%$, without humidification, was used as oxidant reactant. The oxygen gas flow rate was controlled by a mass flow controller (Cole Parmer, CZ-3290767) at constant flow rate of $400 \mathrm{~mL} / \mathrm{min}$. The prepared methanol solution was stored in a storage bag and was driven by a peristaltic pump and sent to a liquid flow meter (Cole Parmer, CZ-32908-43). The oxygen gas and the methanol solution were heated up before flowing into the anode channels. The produced mixtures from DMFC were sent to two separate containers.

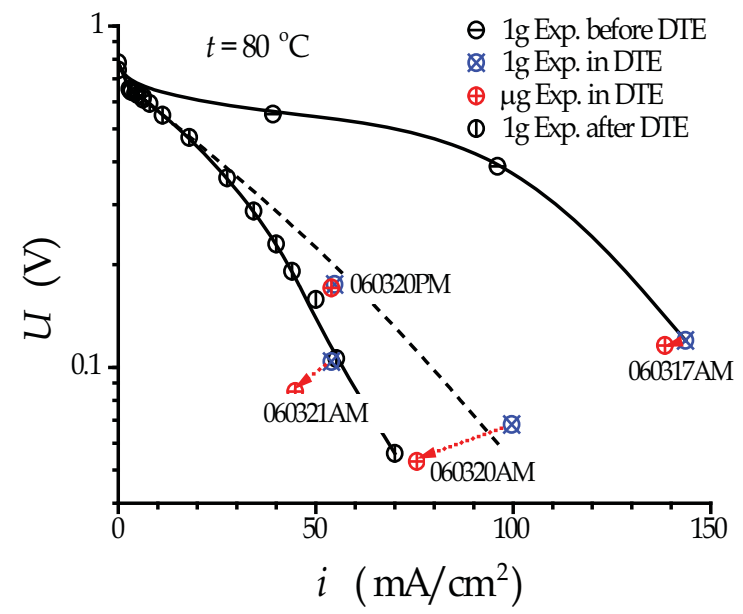

Fig. 13. Influence of gravity on the power performance of DMFC (Wan et al., 2006).

Fig. 13 shows the preliminary results using gold-plating stainless steel as both the anode and the cathode bipolar plates (Wan et al., 2006). In despite of the deterioration of performance of the fuel cell, it is very evident that the cell performance falls more strongly with the degree of concentration polarization deepening.

After re-design of the anode and the cathode bipolar plates, an in-situ visualization of twophase flow inside anode flow bed of a small liquid fed direct methanol fuel cells in normal and reduced gravity has been conducted in a drop tower Beijing. The experimental results indicated that when the fuel cell orientation is vertical, two-phase flow pattern in anode channels can evolve from bubbly flow in normal gravity into slug flow in microgravity (Fig. 14). In normal gravity environment, the gravitational buoyancy is the principal detaching force. The carbon dioxide bubbles were produced uniformly with tiny shape in normal gravity before the release of the drop tower. The diameter of most bubbles, which were detached from the MEA surface, ranged from 0.05 to $0.3 \mathrm{~mm}$ in our experiments (Fig. 14a, corresponding to $40 \mathrm{~ms}$ before the release). After detaching from the MEA surface, the carbon dioxide bubbles moved fast at a speed above $100 \mathrm{~mm} / \mathrm{s}$. Considering that the mean velocity of liquid at the entry of channel was $3.03 \mathrm{~mm} / \mathrm{s}$, which was calculated from the 
inlet flow rate of methanol solution, the speed of bubbles removal was quite fast because of buoyant lift force. Big bubbles with fast velocity would push the small ones anterior. When the bubbles collided with each other, coalescence took place and it was a dominative way of bubbles growth. The typical flow pattern in the anode flow channels in normal gravity was bubbly flow.
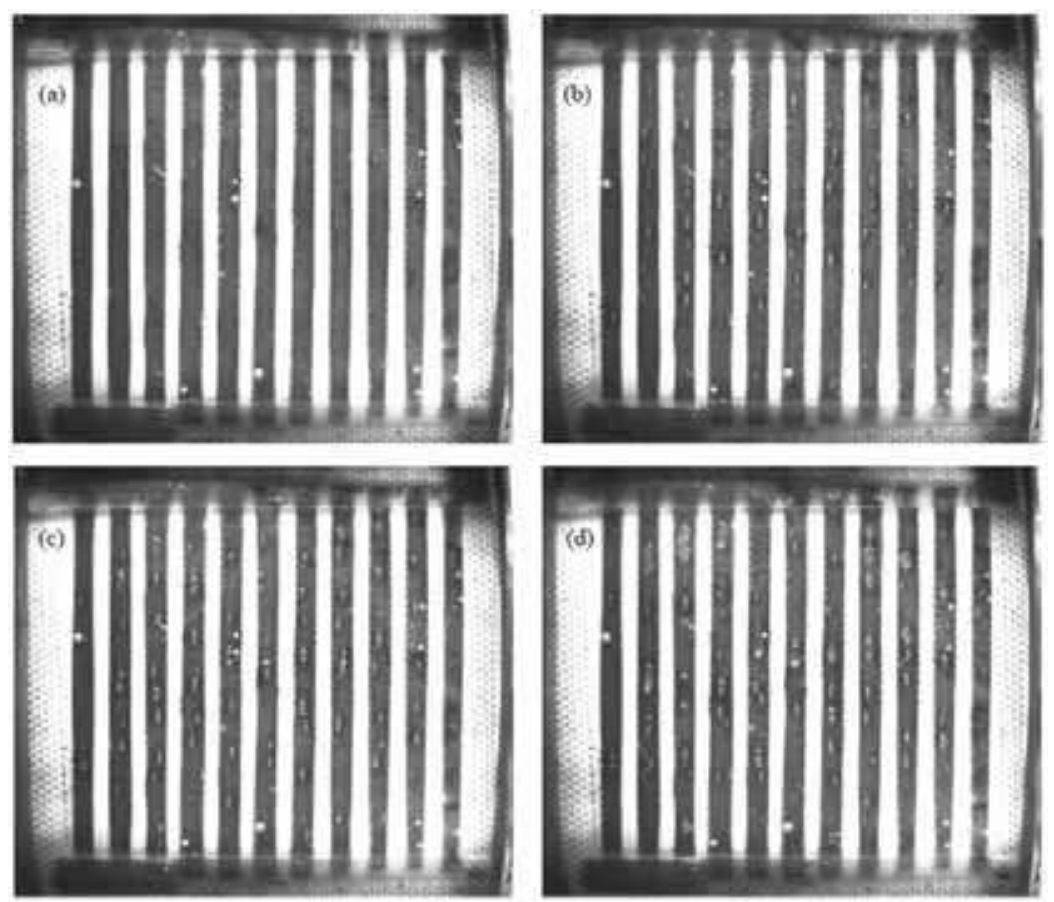

Fig. 14. Gas-liquid two-phase flow pattern in vertical parallel channels of anode bipolar plate of DMFC in different gravity (Guo et al., 2009).

In microgravity, the carbon dioxide bubbles could not get away from the MEA surface in time (Fig. $14 \mathrm{~b} \sim \mathrm{d}$, corresponding to 1,2 and $3 \mathrm{~s}$ after the release, respectively). At the beginning, the bubbles accreted on the wall of carbon cloth surface. Then, the bubbles on the surface grew gradually because of producing carbon dioxide by anode electrochemical reaction. The longer the time was, the bigger the bubble was. Furthermore, the gravity affects not only detaching diameter, but also bubbles rising velocity. The in-situ observation showed that once the capsule was released, the bubbles move was slowed down immediately. Bubbles, which were detached from MEA, almost suspended in methanol solution. The average rising velocities of bubbles in channels are near to the mean velocity of liquid, which was obviously slower than those in normal gravity because buoyancy lift was very weak and the bubbles removal was governed by viscous drag of fluid in the reduced gravity. Some bubbles coalesced with each other and formed larger bubbles. Those large bubbles decreased the effective area of fuel mass transfer and hence the DMFC performance deterioration took place. The gravitational effect on power performance of DMFC is considerable when the concentration polarization is dominant in fuel cells operation. The 
higher the current density is, the bigger the effect of gravity is. Increasing methanol feeding molarity is conducive to weaken the effect of gravity on performance of liquid fed direct methanol fuel cells. Increasing feeding flow rate of methanol solution from 6 to $15 \mathrm{ml} / \mathrm{min}$ could reduce the size of carbon dioxide bubbles. But the influence of gravity still exists (Ye et al., 2010).
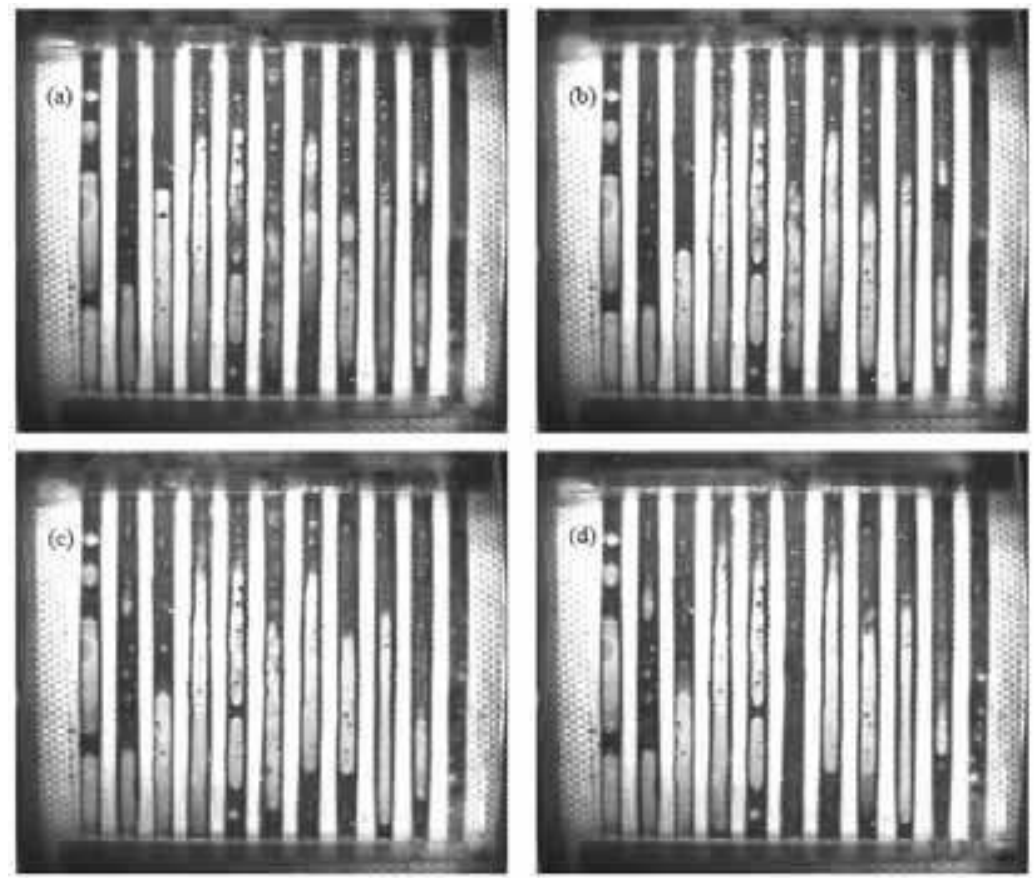

Fig. 15. Gas-liquid two-phase flow pattern in horizontal parallel channels of anode bipolar plate of DMFC in different gravity (Guo et al., 2009).

When the fuel cell orientation is horizontal, the typical flow pattern is the elongated slug flow. The slug flow in the reduced gravity has almost the same characteristic with that in normal gravity (Fig. 15). It implies that the effect of gravity on two-phase flow is small and the bubbles removal is governed by viscous drag. Like in the condition of vertical orientation of fuel cell, once the gas slugs or even gas columns occupy channels, the performance of liquid fed direct methanol fuel cells will fall rapidly. The phenomena infer that in long-term microgravity condition, flow bed, fuel cell orientation and operation condition should be optimized to ensure timely discharge carbon dioxide bubbles and avoid concentration polarization.

A compact transparent proton exchange membrane fuel cell (PEMFC) with a single serpentine channel in graphite cathode flow field, which had a square cross section of $2.0 \times 2.0 \mathrm{~mm}^{2}$ and a rib width of $2.0 \mathrm{~mm}$, was also designed and tested in short-term microgravity environment in the drop tower Beijing. Hydrogen and oxygen gases with purity of $99.999 \%$, without humidification, were used as fuel and oxidant reactant, respectively. The experimental facility was similar with that for DMFC. Its detail can be found in Liu (2008). 
It was found that the accumulated liquid water in the vertical parts of flow channel for the vertical orientation configuration can be removed easily by the reactant gas in microgravity environment comparing with in normal gravity. The PEMFC performance was then enhanced dramatically in microgravity because of the flooded areas in the flow channel before the release of the drop capsule was exposed to the reactant gas again. However, for the horizontal orientation configuration with the lower outlet, liquid water produced in flow channel can move along the bottom of the channel in normal gravity and then flow freely out off the channel. Then little liquid water was found and water columns to pinch off the flow channel were difficult to be formed in normal gravity. On the contrary, the liquid water formed in microgravity was prone to stay in the flow channel, and the departure diameter of water droplets increased. Therefore, the PEMFC performance was deteriorated due to liquid water flooding in the flow channel. The influence of gravity on the characteristics of phase distribution and performance of PEMFC increases with the increase of the current, and/or increase with the decrease of the cell temperature.

\section{Further researches on two-phase flow in microgravity in china}

Several new projects for two-phase flow in microgravity have been proposed to study pressure drop in in-tube condensation, flow boiling heat transfer enhancement of micro-pinfinned surface, membrane separation of two-phase air-water mixture, two-phase flows inside fuel cells and electrolysis cells, and so on. These projects will be helpful for the development of space systems involving two-phase flow phenomena, as well as for the improvement of understanding of such phenomena themselves.

\section{Conclusion}

Two-phase gas-liquid systems have wide applications both on Earth and in space. Gravity strongly affects many phenomena of two-phase gas-liquid systems. It can significantly alter the flow patterns, and hence the pressure drops and heat transfer rates associated the flow. Advances in the understanding of two-phase flow and heat transfer have been greatly hindered by masking effect of gravity on the flow. Therefore, the microgravity researches will be conductive to revealing of the mechanism underlying the phenomena, and then developing of more mechanistic models for the two-phase flow and heat transfer both on Earth and in space.

The present chapter summarizes a series of microgravity researches on two-phase gas-liquid flow in microgravity conducted in the National Microgravity Laboratory/CAS (NMLC) since the middle of 1990's, which included ground-based tests, flight experiments, and theoretical analyses. In the present chapter, the major results obtained in these researches will be presented and analyzed.

Up to now, the sole flow pattern map of two-phase gas-liquid flow in long-term, steady microgravity was obtained in the experiments aboard the Russian space station Mir, which is intended to become a powerful aid for further investigation and development of twophase systems for space applications. Flow pattern map of two-phase air-water flow through a square channel in reduced gravity was obtained in the experiments aboard IL-76 parabolic airplane, too. Mini-scale modeling was also used to simulate the behavior of microgravity two-phase flow on the ground. The criteria of gravity-independence of twophase gas-liquid flow were proposed based on experimental observations and theoretical 
analyses. A semi-theoretical Weber number model was proposed to predict the slug-toannular flow transition of two-phase gas-liquid flows in microgravity, while the influence of the initial bubble size on the bubble-to-slug flow transition was investigated numerically using the Monte Carlo method.

Pressure drops of two-phase flow through a square channel in reduced gravity were also measured experimentally, which were used to validate the common used correlations for microgravity applications. It was found that much large differences exist between the experimental data and the predictions. Among these models, the Friedel model provided a relative good agreement with the experimental data. A new correlation for bubbly flow in microgravity was proposed successfully based on its characteristics, which indicates that there may exist a transition of flow structure in the range of two-phase Reynolds number from 3000 to 4000 , which is similar to the laminar-to-turbulent transition in single-phase pipe flow.

In-situ visualizations of two-phase gas-liquid flow inside fuel cells (DMFC and PEMFC) in different gravity conditions have carried out utilizing the drop tower Beijing. The gravity influence of the cells performance, namely deterioration or enhancement, depends upon the operation conditions. It also infers form the short-term microgravity experiments utilizing the drop tower Beijing that space experiments with long-term microgravity environment are needed.

\section{Acknowledgement}

The studies presented here were supported financially by the National Natural Science Foundation of China (19789201, 10202025, 10432060, 50406010, 50976006), the Ministry of Science and Technology of China (95-Yu-34), the Chinese Academy of Sciences (KJCX2-SWL05), and the Chinese National Space Agency. The author really appreciates Prof. W. R. Hu, Prof. J. C. Xie, Mr. S. X. Wan, Mr. M. G. Wei, and all research fellows who have contributed to the success of these studies. The author also wishes to acknowledge the fruitful discussion and collaboration with Prof. K. S. Gabriel (UOIT, Canada), and Profs. H. Guo and C.F. Ma (Beijing University of Technology, China).

\section{References}

Bousman, W.S., 1995. Studies of two-phase gas-liquid flow in microgravity. Ph.D. thesis, Univ. of Houston, TX.

Carron, I., Best, F., 1996. Microgravity gas/liquid flow regime maps: can we compute them from first principles. In: AIChE Heat Transfer Symp., Nat. Heat Transfer Conf., August, Houston, TX.

Chen, I., Downing, R., Keshock, E., Al-Sharif, M., 1991. Measurements and correlation of two-phase pressure drop under microgravity conditions. J. Thermophy., 5, 514-523.

Cheng, H., Hills, J.H., Azzopardi, B.J., 2002. Effects of initial bubble size on flow pattern transition in a $28.9 \mathrm{~mm}$ diameter column. Int. J. Multiphase Flow, 28(7), 1047-1062.

Colin, C., 1990. Ecoulements diphasiques à bubbles et à poches en micropesanteur. Thesis, Institut de Mécanique des Fluides de Toulouse.

Colin, C., Fabre J., Dukler A.E., 1991. Gas-liquid flow at microgravity conditions-I. Dispersed bubble and slug flow. Int. J. Multiphase Flow, 17(4), 533-544. 
Colin, C., Fabre, J., McQuillen, J., 1996. Bubble and slug flow at microgravity conditions: state of knowledge and open questions. Chem. Eng. Comm., 141/142, 155-173.

Dukler, A.E., Fabre, J.A., McQuillen, J.B., Vernon, R., 1988. Gas-liquid flow at microgravity conditions: flow patterns and their transitions. Int. J. Multiphase Flow, 14(4), 389400.

Dukler, A.E., 1989. Response. Int. J. Multiphase Flow, 15(4), 677.

Gabriel, K.S., 2007. Microgravity Two-phase Flow and Heat Transfer. Springer.

Guo, H., Zhao, J.F., Ye, F., Wu, F., Lv, C.P., Ma, C.F., 2008. Two-phase flow and performance of fuel cell in short-term microgravity condition. Microgravity Sci. Tech., 20(3-4): 265-270.

Guo, H., Wu, F., Ye, F., Zhao, J.F., Wan, S.X., Lv, C.P., Ma, C.F., 2009. Two-phase flow in anode flow field of a small direct methanol fuel cell in different gravities. Sci. China E-Tech Sci, 52(6): 1576 - 1582.

Hewitt, G.F., 1996. Multiphase flow: the gravity of the situation. In: 3rd Microgravity Fluid Physics Conf., July 13-15, Cleveland, Ohio, USA.

Jayawardena, S.S., Balakotaiah, V., Witte, L.C., 1997. Flow pattern transition maps for microgravity two-phase flows. AIChE J., 43(6), 1637-1640.

Lee, J., 1993. Scaling analysis of gas-liquid two-phase flow pattern in microgravity. In: 31st Aerospace Sci. Meeting Exhibit, Jan. 11-14, Reno, NV.

Liu, X., 2008. Two-phase flow dynamic characteristics in flow field of proton exchange membrane fuel cells under micro-gravity conditions. Ph.D. thesis, Beijing University of Technology.

Lowe, D.C., Rezkallah, K.S., 1999. Flow regime identification in microgravity two-phase flows using void fraction signals. Int. J. Multiphase Flow, 25, 433-457.

McQuillen, J., Colin, C., Fabre, J., 1998. Ground-based gas-liquid flow research in microgravity conditions: state of knowledge. Space Forum, 3, 165-457.

Reinarts, T.R., 1993. Adiabatic two phase flow regime data and modeling for zero and reduced (horizontal flow) acceleration fields. Ph.D. thesis, Texas A\&M Univ., TX.

Reinarts, T.R., 1995. Slug to annular flow regime transition modeling for two-phase flow in a zero gravity environment. In: Proc. 30th Int. Energy Conversion Eng. Conf., July 30-August 4, Orlando, FL.

Song, C.H., No, H.C., Chung, M.K., 1995. Investigation of bubble flow developments and its transition based on the instability of void fraction waves. Int. J. multiphase Flow, 21(3), 381-404.

Wallis, G.B., 1969. One-dimensional Two-phase Flow. McGraw-Hill Book Company, New York.

Wan, S.X., Zhao, J.F., Wei, M.G., Guo, H., Lv, C.P., Wu, F., Ye, F., Ma, C.F., 2006. Two-phase flow and power performance of DMFC in variable gravity. 3rd Germany-China Workshop on Microgravity \& Space Life Sciences, October 8 - 11, 2006, Berlin, Germany.

Ye, F., Wu, F., Zhao, J.F., Guo, H., Wan, S.X., Lv, C.P., Ma, C.F., 2010. Experimental Investigation of Performance of a Miniature Direct Methanol Fuel Cell in ShortTerm Microgravity. Microgravity Sci. Tech., 22(3): 347-352.

Zhao J.F., 1999. A review of two-phase gas-liquid flow patterns under microgravity conditions. Adv. Mech., 29(3): 369-382.

Zhao J.F., 2000. On the void fraction matched model for the slug-to-annular transition at microgravity. J. Basic Sci. Eng., 8(4): 394-397. 
Zhao, J.F., 2005. Influence of bubble initial size on bubble-to-slug transition. J. Eng. Thermophy., 26(5), 793-795.

Zhao, J.F., 2010. Two-phase flow and pool boiling heat transfer in microgravity. Int. J. Multiphase flow, 36(2): 135-143.

Zhao, J.F., Gabriel, K.S., 2004. Two-phase flow patterns in a $90^{\circ}$ bend at microgravity. Acta Mech. Sinica, 20(3), 206-211.

Zhao, J.F., Hu W.R., 2000. Slug to annular flow transition of microgravity two-phase flow. Int. J. Multiphase Flow, 26(8), 1295-1304.

Zhao, J.F., Xie, J.C., Lin, H., Hu, W.R., 2001a. Experimental study on two-phase gas-liquid flow patterns at normal and reduced gravity conditions. Sci. China E, 44(5), 553560 .

Zhao, J.F., Xie, J.C., Lin, H., Hu, W.R., Ivanov, A.V., Belyeav, A.Yu., 2001b. Microgravity experiments of two-phase flow patterns aboard Mir space station. Acta Mech. Sinica, 17(2), 151-159.

Zhao, J.F., Xie, J.C., Lin, H., Hu, W.R., Ivanov, A.V., Belyeav, A.Yu., 2001c. Experimental studies on two-phase flow patterns aboard the Mir space station. Int. J. Multiphase Flow, 27, 1931-1944.

Zhao, J.F., Xie, J.C., Lin, H., Hu, W.R., Lv, C.M., Zhang, Y.H., 2001d. Experimental study on pressure drop of two-phase gas-liquid flow at microgravity conditions. J. Basic Sci. Eng., 9(4), 373-380.

Zhao, J.F., Xie, J.C., Lin, H., Hu, W.R., 2002. Pressure drop of bubbly two-phase flow through a square channel at reduced gravity. Adv. Space Res., 29(4), 681-686.

Zhao, J.F., Liu, G., Li, B., 2004a. Two-phase flow patterns in a square micro-channel. J. Thermal Sci., 13(2), 174-178.

Zhao, J.F., Xie, J.C., Lin, H., Hu, W.R., Ivanov, A.V., Belyeav, A.Yu., 2004b. Study on twophase gas-liquid flow patterns at partial gravity conditions. J. Eng. Thermophy., 25(1), 85-87.

Zhao, L., Rezkallah, K.S., 1995. Pressure drop in gas-liquid flow at microgravity conditions. Int J Multiphase Flow, 21(5), 837-849. 


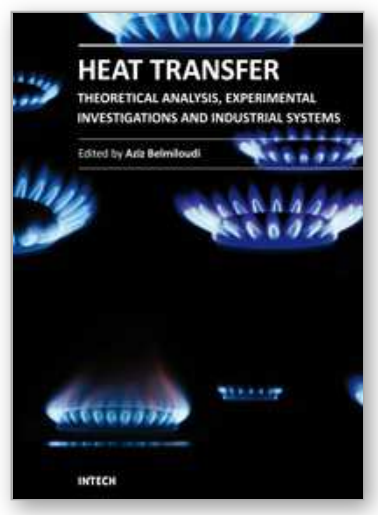

\author{
Heat Transfer - Theoretical Analysis, Experimental Investigations \\ and Industrial Systems \\ Edited by Prof. Aziz Belmiloudi
}

ISBN 978-953-307-226-5

Hard cover, 654 pages

Publisher InTech

Published online 28, January, 2011

Published in print edition January, 2011

Over the past few decades there has been a prolific increase in research and development in area of heat transfer, heat exchangers and their associated technologies. This book is a collection of current research in the above mentioned areas and discusses experimental, theoretical and calculation approaches and industrial utilizations with modern ideas and methods to study heat transfer for single and multiphase systems. The topics considered include various basic concepts of heat transfer, the fundamental modes of heat transfer (namely conduction, convection and radiation), thermophysical properties, condensation, boiling, freezing, innovative experiments, measurement analysis, theoretical models and simulations, with many real-world problems and important modern applications. The book is divided in four sections : "Heat Transfer in Micro Systems", "Boiling, Freezing and Condensation Heat Transfer", "Heat Transfer and its Assessment", "Heat Transfer Calculations", and each section discusses a wide variety of techniques, methods and applications in accordance with the subjects. The combination of theoretical and experimental investigations with many important practical applications of current interest will make this book of interest to researchers, scientists, engineers and graduate students, who make use of experimental and theoretical investigations, assessment and enhancement techniques in this multidisciplinary field as well as to researchers in mathematical modelling, computer simulations and information sciences, who make use of experimental and theoretical investigations as a means of critical assessment of models and results derived from advanced numerical simulations and improvement of the developed models and numerical methods.

\title{
How to reference
}

In order to correctly reference this scholarly work, feel free to copy and paste the following:

Jian-Fu Zhao (2011). Flow Patterns, Pressure Drops and Other Related Topics of Two-Phase Gas-Liquid Flow in Microgravity, Heat Transfer - Theoretical Analysis, Experimental Investigations and Industrial Systems, Prof. Aziz Belmiloudi (Ed.), ISBN: 978-953-307-226-5, InTech, Available from:

http://www.intechopen.com/books/heat-transfer-theoretical-analysis-experimental-investigations-and-industrialsystems/flow-patterns-pressure-drops-and-other-related-topics-of-two-phase-gas-liquid-flow-in-microgravity

\section{INTECH}

open science | open minds

\author{
InTech Europe \\ University Campus STeP Ri \\ Slavka Krautzeka 83/A
}

\author{
InTech China \\ Unit 405, Office Block, Hotel Equatorial Shanghai \\ No.65, Yan An Road (West), Shanghai, 200040, China
}


51000 Rijeka, Croatia

Phone: +385 (51) 770447

Fax: +385 (51) 686166

www.intechopen.com
中国上海市延安西路65号上海国际贵都大饭店办公楼 405 单元 Phone: +86-21-62489820

Fax: +86-21-62489821 
(C) 2011 The Author(s). Licensee IntechOpen. This chapter is distributed under the terms of the Creative Commons Attribution-NonCommercialShareAlike-3.0 License, which permits use, distribution and reproduction for non-commercial purposes, provided the original is properly cited and derivative works building on this content are distributed under the same license. 